\title{
Registros de Marcas dos Clubes de Futebol Brasileiros: análise dos registros de marcas depositados no Brasil
}

\author{
Brand Records of Brazilian Soccer Clubs: analysis of brand records \\ deposited in Brazil.
}

\author{
Andreia Rodrigues Ferreira Baro ${ }^{1}$ \\ Carlos Henrique Calixto dos Santos ${ }^{1}$ \\ Tatiane Luciano Balliano ${ }^{1}$ \\ Victor Xavier Brito ${ }^{1}$ \\ ${ }^{1}$ Universidade Federal de Alagoas, Maceió, AL, Brasil
}

\begin{abstract}
Resumo
O presente artigo tem como finalidade analisar o comportamento dos clubes de futebol que disputam os principais campeonatos de futebol no Brasil no que se refere à proteção de seus símbolos distintivos, sob forma de registro de marca junto ao Instituto Nacional da Propriedade Industrial (INPI). O registro de marcas no Brasil é garantido pela na Lei n. 9.279, de 14 de maio de 1996, chamada de Lei de Propriedade Industrial que dá respaldo legal aos clubes de futebol para que possam proteger os seus símbolos distintivos, contribuindo para a gestão estratégica de marca dos clubes. A proteção da marca garante aos clubes a possibilidade de firmar contratos de licenciamento, cessão e uso das marcas dentro da legalidade, contribuindo para o desenvolvimento dos clubes e de suas estratégias mercadológicas.
\end{abstract}

Palavras-chave: Marketing Esportivo. Prospecção. Registro de Marcas.

\begin{abstract}
The purpose of this article is to analyze the behavior of football clubs that compete in the main soccer championships in Brazil regarding the protection of their distinctive symbols, in the form of trademark registration with the National Institute of Industrial Property - INPI. Trademark registration in Brazil is guaranteed by Law n. 9,279 of May 14, 1996, called the Industrial Property Law and gives legal support to football clubs so that they can protect their distinctive symbols, contributing to the strategic management of brand of clubs. Trademark protection guarantees clubs the ability to enter into licensing, assignment and use agreements within the legal framework, contributing to the development of clubs and their marketing strategies.
\end{abstract}

Keywords: Sports Marketing. Prospecting. Trademark Registration.

Área Tecnológica: Prospecção, Propriedade Industrial. Direito Marcário. 


\section{Introdução}

Atualmente, as relações de consumo estão cada vez mais globalizadas, inclusive o consumo de produtos esportivos, sejam eventos esportivos ou produtos licenciados. $\mathrm{O}$ esporte desempenha papel de destaque no âmbito do entretenimento e figura, cada vez mais, como ator importante nas relações comerciais, ações estratégicas de marketing e publicitárias. E, não poderia ser diferente com os clubes de futebol brasileiro.

O futebol é considerado um esporte com forte apelo emocional, são diversos campeonatos acontecendo em todo o mundo com as mais variadas categorias e classes. A imagem dos clubes de futebol passou a receber maior visibilidade em distintos nichos, deixando de ser algo restrito ao ambiente esportivo. $\mathrm{O}$ futebol deixou de ser um produto meramente voltado para jogos e campeonatos e passou a se relacionar como ator principal da relação de consumo com setores como a indústria têxtil, brindes personalizados, vestuário e outras áreas da indústria de manufaturados.

É possível observar a existência de grandes parcerias entre grandes clubes e marcas dos mais diversos setores da economia, os produtos que carregam a marca de grandes times conseguem atrair a atenção de consumidores torcedores do clube em questão, podendo impactar na decisão de compra. Assim, para evitar que esses produtos sejam copiados e distribuídos ilegalmente, é preciso proteger a marca dos clubes como é feito pelas empresas que ofertam produtos e serviços de outros segmentos.

Hoje, no contexto da economia do conhecimento, a Propriedade Intelectual (PI) desempenha um importante papel como instrumento da estratégia para a competitividade das empresas. A estratégia de posicionar a marca no mercado onde atua de forma estratégica voltada a alcançar novos consumidores está inserida, inclusive, na gestão de clubes de futebol.

No caso dos clubes de futebol, a gestão de marcas passa a ter grande importância para o posicionamento dos produtos licenciados, produtos ofertados pelo próprio clube e serviços personalizados voltados para os torcedores. A marca passa a ser um ativo intangível de notório valor para os clubes, passando a ter atenção especial de seus gestores e investidores.

\subsection{Importância da Proteção da Marca por Clubes de Futebol}

O conceito de marca utilizado neste trabalho segue o conceito definido pelo Manual de Marcas do INPI (2017), que define marca como sendo o sinal visualmente perceptível para os indivíduos, podendo ser figura, logotipo, emblema ou a combinação de todos esses elementos. Ainda em acordo com o Manual de Marcas do INPI (2017), a marca pode ser classificada como: nominativa, figurativa, mista ou tridimensional.

No Brasil, o órgão responsável pelo registro marcas é o Instituto Nacional da Propriedade Industrial (INPI). Esse registro e controle dos sinais registráveis como marca está ancorado na Lei n. 9.279, de 14 de maio de 1996, chamada de Lei de Propriedade Industrial (LPI). A respeito dos sinais registráveis como marca, esses sinais são descritos nos artigos 122 e 123 da Lei de Propriedade Industrial, in verbis: 
Art. 122 São suscetíveis de registro como marca os sinais distintivos visualmente perceptíveis, não compreendidos nas proibições legais.

Art. 123 Para os efeitos desta Lei, considera-se:

I - marca de produto ou serviço: aquela usada para distinguir produto ou serviço de outro idêntico, semelhante ou afim, de origem diversa;

II - marca de certificação: aquela usada para atestar a conformidade de um produto ou serviço com determinadas normas ou especificações técnicas, notadamente quanto à qualidade, natureza, material utilizado $e$ metodologia empregada; $e$

III - marca coletiva: aquela usada para identificar produtos ou serviços provindos de membros de uma determinada entidade.

A proteção de marca relacionada ao futebol está além do registro dos brasões dos clubes, atualmente os clubes estão investindo em lojas, mascotes, slogans e outros símbolos que os representam; sob influência da crescente participação dos clubes de futebol como empresas organizadas e competitivas. As entidades desportivas no Brasil estão cada vez mais profissionalizadas e organizadas, esta organização tem ligação respaldo legal desde a década de 1940 por meio do Decreto-Lei n. 3.199, de 14 de abril de 1941, que estabelece as bases de organização dos desportos em todo o país. Cabe destacar que esse instrumento legal, apesar de tratar da organização e da regulação dos desportos, não permitia que as entidades desportivas obtivessem lucros.

Anos mais tarde, na década de 1990, foi decretada a Lei n. 8.672, de 6 de julho de 1993, que institui normas gerais sobre desportos e dá outras providências; e ficou conhecida como Lei Zico. Sendo o texto legal que possibilitou a transformação de clubes em sociedades comerciais, podendo obter lucros. Em 1998, por meio da Lei n. 9.615 de 24 de março de 1998, chamada de Lei Pelé, as entidades foram passaram a ser tratadas como sociedades comerciais, obrigatoriamente. Porém, nos anos 2000 a obrigatoriedade da equiparação das entidades desportivas as outras sociedades comerciais passaram a ser opcional com o advento da Lei n. 10.672, de 15 de maio de 2003, que alterou a Lei Pelé e deu outras providências.

No Brasil, a entidade responsável por gerenciar e promover o futebol profissional é a Confederação Brasileira de Futebol (CBF), considerada a entidade máxima do futebol nacional, trata-se de uma empresa privada que possui como subordinadas as federações estaduais de futebol. A CBF está localizada na cidade do Rio de Janeiro, estado do Rio de Janeiro e sua fundação data de 24 de setembro de 1979. A atual gestora do futebol brasileiro é uma organização fruto do desmembramento da antiga Confederação Brasileira de Desportos (CBD) que é sucessora da entidade pioneira no futebol brasileiro denominada Federação Brasileira de Sports (FBS), fundada em 8 de junho de 1914.

A CBF organiza o Campeonato Brasileiro, competição que reúne clubes de todo o território brasileiro. Essa competição é dividida em quatro níveis, a Série A, B, C e D, sendo as duas primeiras suas principais competições, conhecidas no passado como Primeira e Segunda Divisões; atualmente 20 clubes disputam a Série A do Campeonato Brasileiro e outros 20 clubes disputam a Série B do Campeonato Brasileiro. Destaca-se que essa competição, de nível nacional, é transmitida em canais de televisão da TV aberta e canais da TV a cabo, além de transmissões em rádios e plataformas digitais, proporcionando aos times e marcas atreladas a eles visibilidade nacional e internacional. 
Essa exposição em diversos tipos de mídias resulta na necessidade dos clubes e patrocinadores de traçar estratégias mercadológicas e publicitárias, com a finalidade de alcançar o público-alvo.

Devido à visibilidade dos clubes de futebol nas mais variadas mídias, algumas empresas passaram a patrocinar clubes que se destacam nas competições, sejam elas nacionais ou regionais; outras empresas buscam comercializar produtos licenciados e pagar os royalties para esses clubes e, inclusive, alguns clubes comercializam, em lojas próprias, diversos produtos.

Entre as empresas patrocinadoras, pode-se observar a presença de bancos públicos, bancos privados, construtoras, empresas do setor alimentício e outras. Desmistificando a ideia de que apenas empresas ligadas ao meio esportivo são atraídas a patrocinar os clubes de futebol. Por isso, a marca é item primordial para a gestão dos clubes, seja a gestão da imagem do clube ou a captação de novos patrocinadores. Faz-se necessário destacar que

[...] o simples fato de possuir um símbolo capaz de distinguir uma empresa dentro do mercado em que atua, empresa pública ou privada, não significa que essa marca está sendo gerida de forma que os aspectos intangíveis estejam sendo explorados e aproveitados ao máximo. (BARO; AMORIM, 2019, p. 206)

Devido à importância de ter a marca do clube registrada, para que os royalties oriundos dos produtos licenciados possam agregar valor ao patrimônio dos clubes, faz-se necessário que os gestores busquem proteger e traçar as melhores estratégias e parceiros para o clube. Uma das vantagens que os clubes podem oferecer aos parceiros que produzem materiais esportivos, ou não, é a existência "[...] do rol dos direitos do detentor da marca, o que impacta diretamente na competitividade da empresa é o direito à exclusividade". Os clubes que optam por proteger a marca, sinal distintivo ou expressão, tem resguardado o direito de explorar essa marca em seus produtos dentro do país em que escolher proteger. Assim:

[...] além do direito de explorar a marca de forma exclusiva, o proprietário pode impedir que outras empresas se utilizem de sua marca para conquistar os clientes, falsificando ou confundindo-os com semelhanças que podem interferir na escolha dos consumidores. (BARO; AMORIM, 2019, p. 207)

\subsection{Importância da Gestão de Marcas para Times de Futebol}

Atualmente, clubes que estão em posição de destaque no campeonato que disputam, times com histórico positivo de partidas vencidas, são considerados fortes, vencedores e bem-sucedidos. Essas características, geralmente atribuídas às pessoas, passam do aspecto individual dos atletas para o aspecto coletivo do grupo, chegando a marca do clube. Esta é considerada a personalidade da marca. Pode-se definir a personalidade da marca como um "[...] conjunto de características humanas associadas a uma marca". (AAKER, 1997, p. 347) ${ }^{1}$. No Brasil o futebol possui forte apelo cultural e a marca dos clubes tende a carregar traços culturais relacionados a cultura do local onde o clube é sediado, das histórias de seus ex-membros e de todo o histórico de derrotas e vitórias em campo. Ainda há poucos estudos que detalham esses aspectos e:

1 "the set of human characteristics associated with a brand" 
[...] pouco se sabe sobre o mecanismo psicológico através do qual a personalidade da marca opera através das culturas. No entanto, pesquisas recentes em psicologia cultural sugerem que o uso simbólico das marcas difere consideravelmente entre culturas. Por exemplo, nas culturas individualistas, onde a independência, a autonomia e a singularidade são valorizadas, os consumidores são mais propensos a usar marcas para expressar como são diferentes de membros do seu grupo. Em contraste, nas culturas coletivistas, onde a interdependência, conformidade e semelhança são valorizadas, os consumidores são mais propensos a usar marcas para expressar como são semelhantes aos membros de seus grupos. (AAKER; SCHMITT, 1997; MARKUS; KITAYAMA, 1991 apud AAKER, 1997, p. 355, tradução nossa) ${ }^{2}$

A confiança que algumas empresas transmitem a seus investidores e patrocinadores pode ser observada nos clubes de futebol da atualidade, a marca de determinados clubes atrai patrocinadores. Os patrocinadores buscam "[...] associar suas marcas a um produto de qualidade e que transmita uma série de conceitos positivos e que trazem maior qualidade de vida, como saúde, entretenimento, plasticidade, competitividade, emoção, alegria, etc." (POZZI, 2000, p. 4). Essa capacidade de atrair patrocinadores, investidores e parceiros comerciais está consolidando o termo "Indústria do esporte". Que pode ser definido como "[...] o mercado no qual os produtos oferecidos aos compradores relacionam-se ao esporte, ao fitness, à recreação ou ao lazer e podem incluir atividades, bens, serviços, pessoas, lugares ou ideias" (PITTS; STOTLAR, 2002 apud ROCHA; BASTOS, 2011, p. 94).

Devido à crescente e vasta divulgação do esporte, algumas empresas passaram a ter interesse em vincular a sua marca a determinado time de futebol com objetivo de aumentar sua exposição na mídia e, consequentemente, aumentar sua participação no mercado em que atua, principalmente, conquistando os torcedores do clube que vinculou sua marca. Esse interesse ganha força, principalmente, porque "[...] o futebol é uma das maiores paixões dos brasileiros e os fatos que cercam esse esporte são constantemente propagados nos diversos meios de comunicação" (LANNA et al., 2017, p. 33).

Assim, toda essa gestão que mantém alinhados conceitos de marketing e desporto quando vistas sob a ótica da propriedade industrial resulta na proteção dos ativos intangíveis do clube; ativos que são capazes de distingui-los diante os inúmeros clubes existentes.

\section{Metodologia}

O trabalho ancora-se na pesquisa descritiva para apresentar a questão disparadora e seus resultados, visto que realiza uma análise descrevendo informações e característica sobre determinada situação. Conforme ensina Malhotra (2010), a pesquisa de cunho descritivo considera as características sobre determinada situação, envolvendo fenômenos ou a sociedade em geral.

Foram obtidos dados junto a base de informações do Instituto Nacional da Propriedade Industrial (INPI). Realizou-se o mapeamento dos depósitos de pedidos de registros de marcas que estão ligados clubes brasileiros de futebol e, posteriormente, a taxa de sucesso destes pedidos - quantos pedidos foram deferidos.

\footnotetext{
2 "[...] little is known about the psychological mechanism by which brand personality operates across cultures. However, recent research in cultural psychology suggests that the symbolic use of brands differs considerably across cultures (Aaker and Schmitt 1997). For example, in individualist cultures, where independence, autonomy, and uniqueness are valued (Markus and Kitayama 1991), consumers are more likely to use brands to express how they are different from members of their in-group. In contrast, in collectivist cultures, where interdependence, conformity, and similarity are valued (Markus and Kitayama 1991), consumers are more likely to use brands to express how they are similar to members of their in-group."
} 
O universo da pesquisa considerou todos os clubes de futebol que disputam o Campeonato Brasileiro Série A e os clubes que disputam o Campeonato Brasileiro Série B. Apesar de não englobar todos os clubes de futebol profissional brasileiros, considerou-se ser apropriado analisar os registros dos clubes com maior relevância na atual fase do futebol nacional quando comparado com a estimativa divulgada pelo clube. Nessa estimativa, foram considerados 40 clubes, 20 deles disputando a Série A e 20 disputando a Série B do Campeonato Brasileiro, que são clubes que representam vários estados do Brasil.

\section{Resultado e Discussões}

Foram analisados todos os depósitos realizados junto ao INPI por clubes de futebol que atualmente disputam o Campeonato Brasileiro (Séries A e B), foram analisados os status dos pedidos e a quantidade destes.

Os 40 clubes que disputam o Campeonato Brasileiro totalizam 1.711 depósitos de pedidos de registros de marca junto ao INPI, dos quais 1.114 estão em vigor, 65 pedidos extintos, 214 aguardando pedido de oposição, 71 indeferidos, 241 arquivados e 10 aguardando pagamento ou inexistentes. Desse total, apenas $12,39 \%$ é originário de times da Série B; se considerarmos apenas os pedidos em vigor na data de escrita deste artigo, esse percentual cai para apenas 10,30\%.

O primeiro clube que atualmente disputa a Série A realizar o depósito de pedido de registro de marca, entre os listados neste artigo, foi o Clube de Regatas Vasco da Gama com o depósito realizado em 1946. Entre os clubes que disputam a Série B atualmente, foi o Guarani Futebol Clube com depósito realizado em 1976.

\subsection{Levantamento Prospectivo de Depósitos de Pedidos de Registros de Marca por Times de Futebol Brasileiros - Registros de Clubes Disputando a Série A}

A pesquisa realizada na Base de Marcas mostra que, juntos, os 20 clubes totalizam 1.526 depósitos de pedidos de registros de marca junto ao INPI. Esses pedidos dividem-se em 1.010 registros em vigor, 45 pedidos extintos, 197 aguardando pedido de oposição, 60 indeferidos, 204 arquivados e 10 aguardando pagamento ou inexistentes.

O primeiro clube a depositar uma marca foi o Clube de Regatas Vasco da Gama em 22 de outubro de 1946. O clube com maior número de depósitos realizados é Grêmio Foot-Ball Porto-Alegrense com 193 depósitos, dos quais 154 pedidos foram concedidos e encontram-se em vigor. Sendo o clube com maior número de registros em vigor na Série A.

Os clubes que possuem menor número de registros concedidos e depósitos realizados são o Goiás Esporte Clube e o Centro Sportivo Alagoano (CSA), ambos com um depósito de pedido de registro e nenhum pedido concedido/em vigor. Vale destacar que o Centro Sportivo Alagoano (CSA) está disputando a Série A do Campeonato Brasileiro pela primeira vez após 31 anos.

A Tabela 1 ilustra a atual situação dos pedidos de registros de marcas pelos clubes na Série A do Campeonato Brasileiro, e demonstra que os clubes reconhecem a necessidade de manter um ativo tão importante protegido. Ressalta-se que os clubes mais tradicionais na disputa de campeonatos com maior nível de profissionalização são os detentores dos maiores números de depósitos. 
Tabela 1 - Times do Campeonato Brasileiro - Série A (ano de referência 2019)

\section{TiMEs}

Data $1^{\circ}$ Pedidos Situação PEDIDO DE MARCA EM VIGOR*
OBSERVAÇÕES

\begin{tabular}{|c|c|c|c|c|c|c|c|c|c|}
\hline $\begin{array}{c}\text { Sociedade } \\
\text { Esportiva Palmeiras }\end{array}$ & $61.750 .345 / 0001-57$ & 07/07/1977 & 100 & 77 & 7 & 6 & 7 & 3 & 0 \\
\hline $\begin{array}{l}\text { Club Athletico } \\
\text { Paranaense }\end{array}$ & 76.710.649/0001-68 & 01/09/1987 & 65 & 20 & 0 & 29 & 1 & 15 & 0 \\
\hline $\begin{array}{l}\text { Clube Atlético } \\
\text { Mineiro }\end{array}$ & 17.217.977/0001-68 & $30 / 12 / 1983$ & 110 & 78 & 3 & 23 & 3 & 3 & 0 \\
\hline $\begin{array}{l}\text { Clube de Regatas } \\
\text { do Flamengo }\end{array}$ & 33.649.575/0001-99 & $17 / 05 / 1966$ & 162 & 123 & 6 & 26 & 2 & 5 & 0 \\
\hline $\begin{array}{l}\text { Associação } \\
\text { Chapecoense } \\
\text { de Futebol }\end{array}$ & 83.018.788/0001-90 & 01/10/2008 & 74 & 27 & 0 & 11 & 11 & 25 & 0 \\
\hline $\begin{array}{c}\text { Esporte Clube } \\
\text { Bahia }\end{array}$ & 15.193.923/0001-84 & 26/12/1988 & 16 & 7 & 0 & 4 & 1 & 4 & 0 \\
\hline $\begin{array}{l}\text { Santos Futebol } \\
\text { Clube }\end{array}$ & 58.196.684/0001-29 & $16 / 05 / 1977$ & 42 & 27 & 3 & 4 & 2 & 6 & 0 \\
\hline $\begin{array}{c}\text { Goiás Esporte } \\
\text { Clube }\end{array}$ & 01.665.256/0001-80 & 18/01/1989 & 1 & 0 & 1 & 0 & 0 & 0 & 0 \\
\hline $\begin{array}{c}\text { Ceará Sporting } \\
\text { Club }\end{array}$ & 07.369.226/0001-03 & $27 / 11 / 2008$ & 24 & 8 & 0 & 16 & 0 & 0 & 0 \\
\hline $\begin{array}{c}\text { Sport Club } \\
\text { Corinthians Paulista }\end{array}$ & 61.902.722/0001-26 & $31 / 01 / 1977$ & 186 & 126 & 4 & 17 & 6 & 32 & 1 \\
\hline $\begin{array}{l}\text { São Paulo } \\
\text { Futebol Clube }\end{array}$ & 60.517.984/0001-04 & $17 / 11 / 1953$ & 181 & 142 & 5 & 9 & 7 & 18 & 0 \\
\hline Avaí Futebol Clube & 77.910.230/0001-12 & $12 / 03 / 2002$ & 8 & 3 & 0 & 0 & 0 & 5 & 0 \\
\hline $\begin{array}{l}\text { Grêmio Foot-Ball } \\
\text { Porto Alegrense }\end{array}$ & $92.797 .901 / 0001-74$ & 13/10/1977 & 193 & 154 & 3 & 13 & 4 & 19 & 0 \\
\hline $\begin{array}{l}\text { Fluminense } \\
\text { Football Club }\end{array}$ & 33.647.553/0001-90 & 18/07/1969 & 59 & 47 & 0 & 8 & 1 & 3 & 0 \\
\hline $\begin{array}{l}\text { Cruzeiro Esporte } \\
\text { Clube }\end{array}$ & $17.241 .878 / 0001-11$ & $11 / 03 / 1983$ & 120 & 51 & 4 & 21 & 9 & 26 & 9 \\
\hline $\begin{array}{l}\text { Sport Club } \\
\text { Internacional }\end{array}$ & 92.894.500/0001-32 & 04/09/1978 & 35 & 22 & 5 & 0 & 0 & 8 & 0 \\
\hline $\begin{array}{c}\text { Botafogo de } \\
\text { Futebol e Regatas }\end{array}$ & $34.029 .587 / 0001-83$ & $21 / 02 / 2008$ & 83 & 58 & 0 & 3 & 4 & 18 & 0 \\
\hline $\begin{array}{l}\text { Club de Regatas } \\
\text { Vasco da Gama }\end{array}$ & $33.617 .465 / 0001-45$ & 22/10/1946 & 40 & 28 & 4 & 3 & 0 & 5 & 0 \\
\hline $\begin{array}{c}\text { Fortaleza } \\
\text { Esporte Clube }\end{array}$ & 07.319.551/0001-61 & 14/12/1995 & 26 & 12 & 0 & 4 & 2 & 8 & 0 \\
\hline \multirow[t]{2}{*}{$\begin{array}{l}\text { Centro Sportivo } \\
\text { Alagoano (CSA) }\end{array}$} & $12.183 .299 / 0001-46$ & 25/06/1997 & 1 & 0 & 0 & 0 & 0 & 1 & 0 \\
\hline & Total & & 1.526 & 1.010 & 45 & 197 & 60 & 204 & 10 \\
\hline
\end{tabular}

Nota: Ex - Extinto; Ag. - Aguardando; Ind. - indeferidos; Ar - Arquivados; Outros - inexistentes e/ou verificar pagamento. Fonte: Elaborada pelos autores deste artigo (2019) 


\subsection{Levantamento Prospectivo de Depósitos de Pedidos de Registros de Marca por Times de Futebol Brasileiros - Registros de Clubes Disputando a Série B}

A pesquisa realizada na Base de Marcas mostra que, juntos, os 20 clubes que disputam a Série B do Campeonato Brasileiro totalizam 189 depósitos de pedidos de registros de marca junto ao INPI. Esses pedidos dividem-se em 104 registros em vigor, 20 pedidos extintos, 17 aguardando pedido de oposição e 11 indeferidos e 37 arquivados.

O primeiro clube a depositar uma marca o Guarani Futebol Clube (SP) em 10 de fevereiro de 1976. O clube com maior número de depósitos realizados é Coritiba Foot Ball Club com 21 depósitos, dos quais 18 pedidos foram concedidos e encontram-se em vigor. Sendo o clube com maior número de registros em vigor na Série $B$.

Os clubes que possuem menor número de registros concedidos e depósitos realizados são o Oeste Futebol Clube com nenhum pedido de registro de marca e Clube Atlético Bragantino com um depósito de pedido de registro e um pedido concedido/em vigor.

A Tabela 2 ilustra a atual situação dos pedidos de registros de marcas pelos clubes na Série $\mathrm{B}$ do Campeonato Brasileiro, e demonstra a tímida atividade de registro de marca pelos clubes. Cabe ressaltar que os clubes que disputam a Série B são clubes com orçamentos menores no cenário nacional de futebol profissional, quando comparados aos clubes que disputam a Série A.

Tabela 2 - Times do Campeonato Brasileiro - Série B (ano de referência 2019)

\begin{tabular}{|c|c|c|c|c|c|c|c|c|c|}
\hline \multirow[t]{2}{*}{ Times } & \multirow[t]{2}{*}{ CNPJ } & \multirow{2}{*}{$\begin{array}{l}\text { DATA 10 } \\
\text { PEDIDOO }\end{array}$} & \multirow{2}{*}{$\begin{array}{c}\text { Pedidos } \\
\text { De marca }\end{array}$} & \multirow{2}{*}{$\begin{array}{l}\text { Situação } \\
\text { EM VIGOR }\end{array}$} & \multicolumn{5}{|c|}{ OBSERVAÇÕES } \\
\hline & & & & & Ext. & Ag. & Ind. & Ar. & Outros \\
\hline $\begin{array}{c}\text { América Futebol } \\
\text { Clube/MG }\end{array}$ & $17.297 .516 / 0001-42$ & 10/09/2001 & 18 & 5 & 0 & 5 & 0 & 8 & 0 \\
\hline $\begin{array}{l}\text { Atlético Clube } \\
\text { Goianiense/GO }\end{array}$ & 01.588.755/0001-11 & $14 / 01 / 2019$ & 2 & 0 & 0 & 2 & 0 & 0 & 0 \\
\hline $\begin{array}{l}\text { Botafogo Futebol } \\
\text { Clube/SP }\end{array}$ & $55.985 .733 / 0001-14$ & $30 / 07 / 2014$ & 2 & 0 & 0 & 0 & 2 & 0 & 0 \\
\hline $\begin{array}{l}\text { Clube Atlético } \\
\text { Bragantino/SP }\end{array}$ & $51.315 .976 / 0001-94$ & 19/12/2013 & 1 & 1 & 0 & 0 & 0 & 0 & 0 \\
\hline $\begin{array}{l}\text { Grêmio Esportivo } \\
\text { Brasil (Brasil } \\
\text { de Pelotas) }\end{array}$ & $90.222 .407 / 0001-56$ & $14 / 06 / 2000$ & 11 & 0 & 1 & 0 & 3 & 7 & 0 \\
\hline $\begin{array}{l}\text { Coritiba Foot } \\
\text { Ball Club/PR }\end{array}$ & 75.644.146/0001-79 & $26 / 12 / 1988$ & 21 & 18 & 1 & 1 & 1 & 0 & 0 \\
\hline $\begin{array}{l}\text { CRB Clube de } \\
\text { Regatas Brasil/AL }\end{array}$ & 12.159.281/0001-09 & $29 / 05 / 2014$ & 6 & 0 & 0 & 2 & 2 & 2 & 0 \\
\hline $\begin{array}{c}\text { Criciúma Esporte } \\
\text { Clube/SC }\end{array}$ & 83.663.781/0001-21 & 15/07/1992 & 12 & 6 & 1 & 3 & 1 & 1 & 0 \\
\hline $\begin{array}{c}\text { Cuiabá Esporte } \\
\text { Clube/MT }\end{array}$ & 04.847.144/0001-39 & 29/12/2009 & 2 & 2 & 0 & 0 & 0 & 0 & 0 \\
\hline
\end{tabular}




\begin{tabular}{|c|c|c|c|c|c|c|c|c|c|}
\hline \multirow[t]{2}{*}{ Times } & \multirow[t]{2}{*}{ CNPJ } & \multirow{2}{*}{$\begin{array}{l}\text { DATA 10 } \\
\text { PEDIDO }\end{array}$} & \multirow{2}{*}{$\begin{array}{c}\text { Pedidos } \\
\text { De marca }\end{array}$} & \multirow{2}{*}{$\begin{array}{l}\text { SituAÇão } \\
\text { EM VIGOR }\end{array}$} & \multicolumn{5}{|c|}{ OBSERVAÇÕES } \\
\hline & & & & & Ext. & Ag. & Ind. & Ar. & Outros \\
\hline $\begin{array}{c}\text { Figueirense } \\
\text { Futebol Clube/SC }\end{array}$ & 83.930.131/0001-03 & 23/12/1992 & 12 & 11 & 0 & 0 & 0 & 1 & 0 \\
\hline $\begin{array}{c}\text { Guarani Futebol } \\
\text { Clube/SP }\end{array}$ & 46.072.179/0001-93 & $10 / 02 / 1976$ & 16 & 09 & 5 & 1 & 0 & 1 & 0 \\
\hline $\begin{array}{l}\text { Londrina Esporte } \\
\text { Clube/PR }\end{array}$ & 75.231.985/0001-65 & 06/06/1984 & 15 & 13 & 1 & 0 & 0 & 1 & 0 \\
\hline $\begin{array}{l}\text { Oeste Futebol } \\
\text { Clube/SP }\end{array}$ & 46.737.250/0001-00 & 0 & 0 & 0 & 0 & 0 & 0 & 0 & 0 \\
\hline $\begin{array}{c}\text { Operário } \\
\text { Ferroviário Esporte } \\
\text { Clube/PR }\end{array}$ & 75.603.316/0001-77 & $25 / 09 / 2009$ & 5 & 2 & 1 & 0 & 0 & 2 & 0 \\
\hline Paraná Clube/PR & 81.907.446/0001-04 & 29/06/1990 & 16 & 10 & 5 & 0 & 0 & 1 & 0 \\
\hline $\begin{array}{c}\text { Associação Atlética } \\
\text { Ponte Preta/SP }\end{array}$ & $46.125 .175 / 0001-26$ & 09/05/1978 & 18 & 13 & 4 & 0 & 0 & 1 & 0 \\
\hline $\begin{array}{l}\text { Esporte Clube } \\
\text { São Bento }\end{array}$ & 71.858.054/0001-30 & 02/09/1991 & 6 & 1 & 0 & 2 & 0 & 3 & 0 \\
\hline $\begin{array}{l}\text { Sport Club do } \\
\text { Recife/PE CNPJ }\end{array}$ & $10.866 .051 / 0001-54$ & 28/02/1994 & 16 & 10 & 0 & 0 & 0 & 6 & 0 \\
\hline $\begin{array}{c}\text { Vila Nova Futebol } \\
\text { Clube/GO }\end{array}$ & 01.669.316/0001-33 & $10 / 08 / 1987$ & 3 & 0 & 0 & 1 & 0 & 2 & 0 \\
\hline \multirow[t]{2}{*}{$\begin{array}{l}\text { Esporte Clube } \\
\text { Vitória/BA }\end{array}$} & $15.217 .003 / 0001-59$ & $21 / 12 / 1984$ & 7 & 3 & 1 & 0 & 2 & 1 & 0 \\
\hline & Total & & 189 & 104 & 20 & 17 & 11 & 37 & 0 \\
\hline
\end{tabular}

Nota: Ex - Extinto; Ag. - Aguardando; Ind. - indeferidos; Ar - Arquivados outros inexistentes e/ou verificar pagamento.

Fonte: Elaborada pelos autores deste artigo (2019)

\subsection{Marca de Alto Renome no Futebol Brasileiro: Caso Flamengo}

A marca de alto renome é o símbolo amplamente conhecido nos mais variados mercados, abrangendo nichos de consumo em geral, e também considerada uma marca de grande reconhecimento. Assim, marca de alto renome tem como características principais a exceção ao princípio da especialidade, ser de alto conhecimento do público em geral e reputação positiva e é protegida em todos os ramos de atividade econômica.

O registro da marca de alto renome no Brasil tem duração de 10 anos o primeiro período de concessão, podendo ser renovado por igual período por tempo indeterminado. Esta garantia de proteção ampla é garantida por lei, conforme prevê o artigo 125 da Lei n. 9.279/96, LPI, in verbis, "Art. 125. À marca registrada no Brasil considerada de alto renome, será assegurada proteção especial em todos os ramos de atividade".

A importância do registro de marca é essencial para as empresas que possuem grande reconhecimento positivo junto ao público consumidor de variados mercados, e não há diferença para os clubes de futebol. 
No início do ano de 2019, o Clube de Regatas Flamengo foi o primeiro time de futebol brasileiro a ter o deferimento do reconhecimento de sua marca como marca de alto renome, alcançando o status que possibilita ao clube explorar mercadologicamente o benefício de possuir um tratamento diferenciado e proteção adicional. Esse tratamento diferenciado se dá porque nenhum estabelecimento comercial, produto ou serviço não poderá utilizar a marca do clube, independente de qual setor da economia seja, conforme estabelecido no artigo $1^{\circ}$ da Resolução n. 107/13 do INPI.

A Tabela 3 representa o despacho publicado na Revista de Propriedade Industrial do INPI, que confere ao Flamengo o status de marca de alto renome.

Tabela 3 - Despacho RPI

\begin{tabular}{|c|c|c|c|c|}
\hline RPI & Data RPI & Despacho & IMG & Complemento do Despacho \\
\hline 2504 & 02/01/2019 & $\begin{array}{l}\text { Recurso } \\
\text { provido } \\
\text { (outros) }\end{array}$ & - & $\begin{array}{c}\text { Protocolo: } 850160061234 \text { (28/03/2016) } \\
\text { Petição (tipo): Recurso contra decisão em petição (333.18) } \\
\text { Requerente(es): CLUBE DE REGATAS DO FLAMENGO } \\
\text { Procurador: Montaury Pimenta, Machado } \\
\text { \& Vieira de Mello Advogados } \\
\text { Detalhes do despacho: Recurso conhecido e provido. } \\
\text { Reformado o ato recorrido. Deferido o pedido de } \\
\text { Alto Renome da marca de apresentação nominativa } \\
\text { FLAMENGO, registrada sob o }{ }^{\circ} \text { 006085547, de titularidade } \\
\text { de CLUBE DE REGATAS DO FLAMENGO. }\end{array}$ \\
\hline
\end{tabular}

Fonte: INPI (2019)

Esse reconhecimento da marca do Clube de Regatas Flamengo como marca de alto renome demonstra a importância do registro de marca para os clubes de futebol, desmistificando a ideia de que a proteção de marca deve ser vislumbrada apenas por empresas que produzem ou prestam serviços.

\section{Considerações Finais}

O desenvolvimento do presente trabalho possibilitou uma análise da importância da proteção da marca pelos clubes de futebol brasileiro.

A exploração comercial da imagem dos clubes, por meio de royalties gerados, venda de produtos ou patrocínios, é uma realidade que impõe aos gestores dos clubes a proteção dos símbolos distintivos dos clubes de futebol. Essa proteção, garantida por lei, possibilita a esses gestores a obtenção de ganhos com a exploração da marca por meio das mais variadas estratégias comerciais. No Brasil, o registro de marcas de clubes de futebol ainda registra números baixos quando comparados a outros setores da economia.

Ao comparar o número de depósitos de registros de marcas dos clubes que disputam as duas séries do Campeonato Brasileiro de futebol profissional, pode-se chegar à conclusão de que existe uma enorme discrepância entre os valores. Os clubes da Série A detêm 87,61\% do total dos pedidos registrados ao longo da história; se considerarmos apenas o montante dos pedidos em vigor na data de escrita deste artigo, esse percentual é de 89,70\%. Esses valores demonstram o nível de interesse pelo tema e o valor dado à proteção desse ativo intangível de extrema importância para os clubes, especialmente aqueles de maior expressão no mercado, que são os da Série A. 
Os clubes que disputam a Série A possuem orçamento e patrimônio maior do que os clubes que disputam a Série $\mathrm{B}$, essa diferença patrimonial pode interferir na gestão de marcas dos clubes, pois os contratos de cessão e licenciamento são mecanismos que impulsionam a proteção das marcas. Os clubes que estão disputando a chamada "elite" do futebol nacional, Série A, estão familiarizadas a negociações e contratos, o que acaba influenciando positivamente no processo de proteção e registro de suas marcas.

Dessa forma, é preciso que os clubes que possuem orçamentos e patrimônios menores passem, cada vez mais, a proteger as suas marcas, pois, com o advento das plataformas digitais, há a crescente necessidade de garantir que o uso indevido de suas marcas não seja indevido.

A proteção da marca garante aos clubes a possibilidade de firmar contratos de licenciamento, cessão e uso das marcas dentro da legalidade, contribuindo para o desenvolvimento dos clubes. A cessão implica total entrega da titularidade da marca em relação ao titular, em benefício do cessionário, e a licença de uso se restringe ao direito de exploração por parte do beneficiário, continuando a titularidade vinculada ao clube proprietário da marca.

Sendo assim, o registro de marca possibilita aos clubes a exploração de forma adequada e estratégica das marcas que são detentores, além da possibilidade de agir com respaldo legal contra as contrafações/pirataria dos produtos esportivos que por ventura venham a comercializar, ou que sejam comercializados por empresas que possuem a autorização de uso da marca.

\section{Referências}

AAKER, J. L. Dimensions of Brand Personality. Journal of Marketing Research, [S.I.], v. 34, n. 3, 1997. Disponível em: https://journals.sagepub.com/doi/abs/10.1177/002224379703400304. Acesso em: 14 jun. 2019.

BARO, Andreia. R. F; AMORIM, J. F. O. Propriedade Industrial em Alagoas: uma Análise dos Depósitos de Marcas em Alagoas. Cadernos de Prospecção, Salvador, v. 12, n. 1, p. 204-218, março, 2019. Disponível em: https://portalseer.ufba.br/index.php/nit/article/view/27280/16973. Acesso em: 28 abr. 2019.

BRASIL. Decreto-Lei n. 3.199, de 14 de abril de 1941. Estabelece as bases de organização dos desportos em todo o país. Brasília, DF, 1941. Disponível em: http://www.planalto.gov.br/ccivil_03/ Decreto-Lei/1937-1946/Del3199.htm. Acesso em: 30 jun. 2019.

BRASIL. Lei n. 8.672, de 6 de julho de 1993. Institui normas gerais sobre desportos e dá outras providências. Brasília, DF, 1993. Disponível em: http://www.planalto.gov.br/ccivil_03/Leis/L8672.htm. Acesso em: 30 jun. 2019.

BRASIL. Lei n. 9.615, de 24 de março de 1998. Institui normas gerais sobre desporto e dá outras providências. Disponível em: http://www.planalto.gov.br/ccivil_03/LEIS/L9615consol.htm Acesso em: 30 jun. 2019.

BRASIL. Lei n. 10.672, de 15 de maio de 2003. Altera dispositivos da Lei n. 9.615, de 24 de março de 1998, e dá outras providências. Brasília, 2003. Disponível em: http://www.planalto.gov.br/ ccivil_03/Leis/2003/L10.672.htm. Acesso em: 30 jun. 2019. 
INPI - INSTITUTO NACIONAL DA PROPRIEDADE INDUSTRIAL. 2019. Disponível em: http://www.inpi.gov.br/menu-servicos/marcas/arquivos/inpi-marcas_-marcas-de-alto-renome-emvigencia_-12-02-2019_padrao.pdf/view. Acesso em: 20 jul. 2019.

INPI - INSTITUTO NACIONAL DA PROPRIEDADE INDUSTRIAL. Manual de Marcas. 2. ed. [S.l.]: INPI, 2017. Disponível em: http://manualdemarcas.inpi.gov.br/projects/manual-de-marcas-2-edicao1-revisao/wiki/Manual_de_Marcas Acesso em: 30 jun. 2019.

LANNA, Giovani Blasi Martino et al. Reconhecimento das marcas patrocinadoras dos times de futebol brasileiro. Revista Brasileira de Futsal e Futebol, São Paulo, v. 9, n. 32, p. 32-36. jan./ fev./mar./abril. 2017. ISSN 1984-4956. Disponível em: http://www.rbff.com.br/index.php/rbff/issue/ view/34 Acesso em: 14 jun. 2019.

MALHOTRA, Naresh K. Pesquisa de Marketing: uma orientação aplicada. São Paulo: Bookman, 2010.

POZZI, Luis Fernando. Os riscos do Marketing Esportivo. RAE - Revista de Administração de Empresas, EAESP, FGV, São Paulo, v. 7 n. 4 p. 4-5, out.-dez. 2000. Disponível em: http://www. scielo.br/pdf/rae/v40n4/v40n4a13.pdf. Acesso em: 28 abr. 2019.

ROCHA, Cláudio M.; BASTOS, Flávia da Cunha. Gestão do Esporte: definindo a área. Rev. bras. Educ. Fís. Esporte, São Paulo, v. 25, Edição Especial, p. 91-103, dez. 2011. Disponível em: http:// www.scielo.br/pdf/rbefe/v25nspe/10.pdf. Acesso em: 28 abr. 2019.

\section{Sobre os Autores}

\section{Carlos Henrique Calixto dos Santos}

E-mail: chcalixto@gmail.com

Mestrando pelo Programa de Pós-Graduação em Propriedade Intelectual e Transferência de Tecnologia para a Inovação (PROFNIT) em 2019. Especialista em Gestão da Inovação e Competitividade (UFAL) em 2008. Graduado em Administração (CESMAC) em 2000.

Endereço profissional: Universidade Federal de Alagoas, Campus A.C. Simões. Av. Lourival de Melo Mota, s/n, Tabuleiro dos Martins. CEP: 57072-900.

\section{Andreia Rodrigues Ferreira Baro}

E-mail: andreiabaro@hotmail.com

Mestranda pelo Programa de Pós-graduação em Propriedade Intelectual e Transferência de Tecnologia para a Inovação (PROFNIT) em 2019. Mestre em Ciências da Educação pela Universidad Interamericana em Assunção, Paraguai, em 2018). Graduada em Administração (FAL) em 2008.

Endereço profissional: Universidade Federal de Alagoas, Campus A.C. Simões. Av. Lourival de Melo Mota, s/n, Tabuleiro dos Martins. CEP: 57072-900.

\section{Victor Xavier Brito}

E-mail:victorxb3@gmail.com

Mestrando pelo Programa de Pós-Graduação em Propriedade Intelectual e Transferência de Tecnologia para a Inovação (PROFNIT) em 2020. Graduado em Ciências Biológicas (UFAL) em 2010.

Endereço profissional: Universidade Federal de Alagoas, Campus A.C. Simões. Av. Lourival de Melo Mota, s/n, Tabuleiro dos Martins. CEP: 57072-900. 


\section{Tatiane Luciano Balliano}

E-mail: tlb@qui.ufal.br

Doutora em Física Aplicada (Biomolecular) pela Universidade de São Paulo (USP) em 2010. Mestre em Química e Biotecnologia, área de concentração Físico-química (cristalografia de raios $\mathrm{X}$ ) pela Universidade Federal de Alagoas (UFAL) em 2006.

Endereço profissional: Laboratório de Bioprocessos, Cristalografia e Modelagem Molecular - LABIOCriMM.

Universidade Federal de Alagoas, Campus A.C. Simões. Av. Lourival de Melo Mota, s/n, Tabuleiro dos Martins. CEP: 57072-900. 